Foro Interno. Anuario de Teoría Política

ISSN: $1578-4576$

http://dx.doi.org/10.5209/rev_FOIN.2015.v16.53887

\title{
Desde la frontera: Ocupaciones y apropiaciones
}

[en] From the Border: Occupying and Appropriating

Tenía miedo de las noches que le llenaban de fantasmas la oscuridad. De encerrarse con sus fantasmas. De eso tenía miedo ${ }^{1}$.

Dentro de la tendencia actual a sustituir la ley por la voluntad del pueblo, estamos viendo cómo con frecuencia se menciona el hecho de ocupar como una manera legítima de apropiarse algo en la vida. Incluso en el catálogo de movimientos alternativos, se presentan los okupas como héroes antisistema que desafían la maldad o insensibilidad de las leyes, muchas de ellas podridas por la inercia o la torpeza de los gobiernos.

Estos okupas llegan a ser una esperanza de mucha gente que se siente asfixiada por el sistema legal en marcha, pero también resulta una amenaza para los que confían y sostienen la ley y el orden.

La palabra tiene antecedentes de lujo en términos como asaltar, invadir, reconquistar y otros. Son ideas consagradas en la historia de los países como algo beneficioso. Sirven para poner las cosas en su sitio, donde debían estar y no estaban, o para dar un fuerte avance a la humanidad.

Las ocupaciones, en realidad, siempre han tenido mucho que ver con hacerse con terrenos y otros bienes que no nos pertenecían. Los tomamos ahora, generalmente con violencia, y los hacemos nuestros. Podemos alegar que no estaban registrados, que son simplemente recuperaciones de algo que es metafísicamente nuestro, o que son lugares que no están poseídos de manera legal. Lo legal y lo legítimo, palabras con las que los periodistas y expertos se sienten seguros, serán para los ocupantes la misma cosa desde el momento en que la ley democrática se considere expresión directa, casi emanación de la voluntad del pueblo.

Los ocupantes de las culturas alternativas son hoy considerados como un fenómeno nuevo, arisco e indomable, con frecuencia asociado con fuentes de vida como la juventud, el idealismo, el rechazo de los defectos de nuestros sistemas y la libertad. Visto así, tiene su parte romántica y dulce.

Lamentablemente, no es ese el caso. Para empezar, en general el fenómeno no es nuevo, sino el mismo que han protagonizado sus padres recientemente.

En las dos grandes culturas de gobernanza contemporáneas, (i) la calvinista (ellos mismos prefieren llamarse puritanos, con su despliegue pulcro y ansioso de un destino) y (ii) la católica, llena de magia y omnipotencia, los modos de ocupar difieren. Los calvinistas siempre se lanzan a la persecución: persiguen la felicidad

Juan Rulfo, Pedro Páramo (1955), RM Verlag, Barcelona, 2011, p. 109. 
(the pursuit of happiness) y persiguen entre sí a los malos, a los que no hacen lo correcto. Como ocurre en los Estados Unidos, el país emblemático de este tipo de sociedad, siempre están yendo al oeste. Van a cumplir con un destino que algunos de sus próceres piensan incluso que es un destino manifiesto (manifest destiny).

Los católicos no hacen uso de esos delirios paranoides y se centran obsesivamente en llegar a los puestos, plazas o territorios y ocuparlos. Aposentarse allí para no moverse ni ser movido (sentarse encima, besitzen, possidere). Su futuro se tejerá sobre una consideración omnipotente de la política: la de que los deseos se conviertan en realidad, pese a quien pese, y vayan tejiendo la conducta pública y privada. Una vez que ellos estén ya en sus cargos - ya tengan su plaza - pasarán como estrategia a incorporar a sus parientes, amigos e incondicionales. Es decir, la magia llevada a lo público.

El hecho de que en una zona rija la visión mágica de la política significa que en ese ambiente civil el tiempo y el espacio quedan muy relativizados, ya que en el mundo interno en donde se desarrollan los caprichos, los deseos que brotan y saltan sobre la realidad, no existe el principio de identidad. Obviamente en estas culturas se cumple con los horarios y transcurre la vida en las barrancas, las plazas o los puertos de mar. Y ello requiere de encuentros y desencuentros cotidianos. Pero, en el fondo, estas acciones quedan muy debilitadas en cuanto a su reflejo administrativo o empresarial; y lo mismo ocurre con su gobernanza. El tiempo está siempre sometido al vaivén de las olas y tormentas de los deseos imperiosos de los individuos: $a \mathrm{su}$ real y soberana gana. La puntualidad pasa a segundo término, como una manía extranjeriza; los protocolos y la planeación se someten a lo que allí se llama la ley del mercado, pero que más bien resulta ser el capricho y las necesidades perennes de los poderosos y los empresarios. Un juego de espejos mareante manejado por los especuladores (speculum) y los supervivientes. Los ciudadanos en esos lugares utilizarán el desarrollo teórico político que implica el libre albedrío: el libero arbitrio latino de Agustín de Hipona (354-430) y Anselmo de Aosta (1033-1109). Las fronteras de los estados entre culturas de gobernanza divergente (Tijuana/San Diego, Ciudad Juárez/El Paso) adquieren un fulgor especial: abiertas, muy peligrosas y de desarrollo económico intenso.

Un problema en ambas variantes administrativas es que nadie es consciente de que ello implique un deslizamiento de la sabiduría del buen juicio. La ley pasa a quedar circunscrita en su validez a un territorio, con lo que los interesados empiezan a ser beneficiarios de un reglamento en vez de una ley. Ellos, los de dentro, serán convertidos automáticamente en árbitros que, en mayor o menor medida, cuentan con la aplicación del reglamento del recinto, dando siempre su opinión, su laudo arbitral, como última palabra inmediata e inapelable. Y casi, como los árbitros deportivos, a toque de silbato. Todo ciudadano será así "juez" (en realidad, árbitro). Como pretendía el Partido Soviético: "Que toda la población obrera, sin excepción, se incorpore a la función judicial" ". Aquello no debió salir del todo bien; pero quedaba el consuelo de que, como alegaba el camarada Chulpeniov: "Lo importante es que nosotros nos hemos mostrado vigilantes"3.

Programa del VIII Congreso Partido Soviético de 1919. Citado en Alexsandr Solzhenitsyn, Archipiélago Gulag (1918-1956) (2 vols.), Mondadori Printing, Italia, 2002, vol. 1, p. 340.

Ibid., p. 347. 
El anclaje de la conducta mágica es el de los asentamientos. En esa situación se tiende a poner en curso un tiempo eterno y los vaivenes de la política siempre serán guerra-civilistas. En el pensamiento omnipotente, del que todos los humanos hemos aprendido en épocas muy tempranas de nuestra vida, o bien se es bueno o se es malo; o se ama o se odia. No se concibe, como haremos ya más adultos, que las cosas haya que mezclarlas y aceptarlas en su hibridación: admitir que no puede haber soluciones finales para todo. La administración pública de estos países de cultura mágica adolecerá de esta flexibilidad para acordar, pactar y terminar las cosas. Concebir la política como algo más concreto que simplemente hablar con verborrea o en tono místico; y en donde los problemas prácticos han de solucionarse con renuncias a nuestra propia omnipotencia. Hoy sabemos que la omnipotencia es siempre estéril.

El problema en la actualidad es que, con la globalización de la vida del planeta, las dos culturas modernas de origen europeo se entrelazan constantemente y se generan roces muy agrios. Los países persecutorios no paran de patrullar el mundo con sus ejércitos y espías, todos ellos funcionarios, que entran y salen de otros estados sin dar cuentas a nadie más que a sus superiores. Entrarán y se replegarán de los países dejando detrás implantes manipulables y llevándose consigo el control remoto de sus bienes y recursos, sean estos su petróleo o las mejores posiciones estratégicas. Dejarán tras sí accesos abiertos a sus fines.

Los regímenes que utilizan recursos de las sociedades mágicas invaden y se quedan plantados en los territorios de otros. Es evidente que, para poder hacerlo, tendrán que alegar que no eran de nadie (bienes mostrencos) y que están limpiando esos territorios de algo muy dañino para la vida y por tanto para la humanidad: sus ideas perniciosas, alguna idolatría o sus prácticas viciosas respecto a toda la especie humana. A veces, como en los nacionalismos internos, se trazan líneas y se crean espacios cerrados que se quieren preparar con un nuevo reglamento/Constitución para los que son de dentro. Aquí la apropiación requeriría de previas expulsiones, anulación de identidades, expropiaciones masivas y proclamaciones desafiantes.

La ciencia política del siglo veinte, empantanada en las ideologías vigilantes, ha pretendido desarrollar una ingeniería de lo público que ha dado buenos resultados. Pero solo hasta cierto punto. Porque uno de los errores más graves de esta politología, como un tanto ridículamente se dice ahora, lo ha heredado del propio derecho público. Unos y otros han convivido, de manera sorprendente, con ese estudio y descripción que hacen del Estado como maquinaria entendida siempre, o casi siempre, hacia dentro. La Staatslehre o teoría del Estado del siglo veinte desmonta y define los elementos del Estado aceptando desde el principio como esencial la necesidad de un territorio.

Ya vemos ahora cómo muchos estados están queriendo desdibujar la importancia de ese territorio. En algunos casos con acuerdos comerciales entre zonas geográficas que incluyen a varios estados, en otros, con uniones más íntimas como la Unión Europea; por no mencionar el reto de esos nuevos espacios a conquistar como el espacio estelar y los foros públicos de internet.

\section{Megapolítica}

En la sociedad vigilante, la ciencia política del mundo calvinista deforma el estudio del Estado, ignorando el comportamiento de esta gigantesca maquinaria en el ámbito 
de la megapolítica. Si lo tuvieran en cuenta, se encontrarían con que esa supuesta característica identificativa de la sociedad liberal que la empuja a la libertad de mercados y a la separación y equilibrio de poderes, tendría que retirarse. Los estados nunca subcontratan el mando de sus ejércitos ni de sus servicios de inteligencia. En la megapolítica los mecanismos estatales son por definición monopolísticos.

Pero claro está que, para la sociedad vigilante, la vida es una guerra perpetua y la alerta de la ciudadanía debe ser máxima y veinticuatro horas al día. En palabras de Jean Calvin (1509-1564), el individuo ha de vivir como si tuviera un cuchillo en la garganta. Una militarización de la política que afectará, se quiera o no, a la gestión pública y producirá una lluvia constante de tics de monopolio.

$\mathrm{Si}$ en la gobernanza intraestatal la gestión de inspiración calvinista ha dado resultados impresionantes por sus triunfos, por su capacidad de extirpar la guerra civil de sus calles y ciudades, y por el impresionante acierto en el diseño de sus instituciones, no se puede decir lo mismo al pasar al espacio exterior.

En su caso, las sociedades de tradición mágico-omnipotente dejan mucho que desear en comparación con los puritanos en cuanto a su capacidad de autogobierno y defensa de sus territorios. Plagadas de guerras intestinas y muy confusas en sus prácticas institucionales, se duelen de heridas internas incurables. Estas son principalmente la corrupción sistemática de sus políticos y una fragmentación tal del saber y la autoridad que permite la aparición de miles de genios y analistas que lo saben todo y lo pueden explicar todo: son sociedades hiperdiagnosticadas. Sabios y sabidurías que con frecuencia arrasan sin construir y desactivan a los más independientes y creativos. Sus prácticas centenarias ostentan una cultura de pudor y denuncia cuya solución suele estar en destaparse para controlar, en una transparencia que parece ser un desnudarse para, ¡de una vez por todas!, acabar con los escondrijos y los hábitos de hurtar las cosas a la mirada pública. En el centro, la amedrentadora plaza mayor como símbolo aristotélico de ese espacio en que todo el mundo ve a todo el mundo, con la banda sonora de la delación y el denuncismo.

Ahora bien, esos defectos, que han relegado estos países a una segunda línea mundial, les han hecho perder millones de kilómetros cuadrados de territorio ${ }^{4}$ y a ser desprovistos de recursos inmensos. Se puede decir que sus maquinarias estatales, hasta el momento en que estamos, apenas si han podido llegar a ser un contendiente serio en cuanto a la estabilidad del planeta. No por falta de deseo patriótico ni de intentos políticos, sino por falta de recursos y por su debilidad en la competencia.

Con la llegada de la globalización, en la que estamos metidos de 1leno, el contacto de ambas culturas se ha hecho imparable. Por supuesto que con la adición de otras tradiciones del Pacífico, culturas muy antiguas y llenas de innovación. Sociedades escarmentadas con esas ideologías vigilantes que las han tenido atenazadas y ensimismadas.

Va a resultar muy interesante la mezcla, ya en marcha, de esas gobernanzas modernas expandidas y articuladas a través de las dos lenguas occidentales de alcance intercontinental: el inglés y el español. Invasión persecutoria y ocupación omnipotente tendrán que hibridarse en buena medida.

Valga como ejemplo el Tratado de Guadalupe Hidalgo ("Tratado de Paz, Amistad, Límites y Arreglo Definitivo" de febrero de 1848) entre México y EE. UU. México perdió dos millones de kilómetros cuadrados de su territorio. 
La brutalidad de la cultura administrativa de raíz puritana en el exterior y la fracasada, pero socialmente expansiva, de las sociedades de la omnipotencia, el libre albedrío y la real gana, serán elementos decisivos en la gobernanza de nuestro siglo.

Claro que, mientras tanto, los jóvenes de todo el planeta se comunican y educan entre sí, y el teléfono planetario ya es gratis. La pedagogía, las prácticas morales e incluso nuestros partenaires en la vida diaria no reconocen las fronteras. Los espacios públicos internos de la gente se están mundializando a una velocidad importante. De ahí que la autonomía de lo financiero y de las nuevas fantasías vaya creciendo como una realidad inmensa. Algo desbordante e incomprensible para una ciencia política perpleja que, como ha hecho con las amenazas nucleares, ni siquiera lo intenta explicar. 